\title{
AN ARTERIAL INJURY IN THE WESTERN DESERT 1942
}

\author{
St. J. D. BUXTON, M.B., B.S., F.R.C.S. \\ formerly Consulting Surgeon (Orthopaedic) M.E.F. \\ and \\ Honorary Consultant in Orthopaedic Surgery to the Army
}

\section{Introduction}

ON the third of June 1942 G. A. G. Mitchell, now Professor of Anatomy in the University of Manchester, and I left Cairo travelling by road through the Nile Delta to Alexandria and onwards to Sollum.

When we arrived at Sollum we found a tented unit at 2 nd Indian C.C.S., on the south of the road, and between the road and the sea shore the well equipped Hadfield Spears Hospital with its nursing sisters. A few casualties were being admitted to the C.C.S., some of the wounded belonging to the 10th Indian Field Ambulance, which had been bombed.

There had been few opportunities for me to see casualties soon after wounding. The advantage of doing so was to take note of severe or unusual injuries and to see the work of the surgeons in forward areas. If one managed to see certain wounded men at forward units and subsequently again at base hospitals, information on their progress could be passed to the surgeons in the forward area; this enabled them to learn from experience and, of course, it much encouraged them in their work.

\section{An Arterial Injury}

Among the casualties admitted in the evening was a soldier hit through the calf. The surgeon of this unit was impressed by his pain, and by the shape of his calf, which was distended and tense so that the circumference of the leg was increased; the wound was smaller than a sixpenny piece and was oozing; the dressing was damp but not saturated with blood; the foot was cooler than the other; he did not like moving his ankle which caused pain. There was doubt about recognition of pulsation of the posterior tibial artery behind the medial malleolus, the man found it difficult to answer questions about sensation on the dorsum and sole of the foot. Pricking the sole caused the foot to be drawn up but did not appear to cause the normal discomfort of this test.

The signs were significant and pathognomonic of interference with this artery about the centre of the calf. As there were no casualties requiring immediate operation, the surgeon invited me to operate on this limb.

The conditions for surgery in the C.C.S. were of the simplest-a small tent, a portable operating table, a sterilizer on a primus stove and a lamp quite insufficient for most purposes, but an Indian orderly enjoyed being a "spotlight boy" with electric torches and was most helpful; in fact, there was little variation from the normal ritual of an operation. The anaesthetised man had a tourniquet applied round the lower third of the thigh and was then placed in the prone position. The ragged entry wound was excised and skin incision carried upwards and downwards so that it was 5 inches in length. When the wound had been examined before the operation, only clot was seen deep to the skin edges, but now it was laid open, it was obvious that blood clot was adherent to a piece of gauze, presumably inserted to stop haemorrhage. This was removed, appeared clean, 
but small particles of a textile material were adherent to it. Some blood oozed out, while the débridement was carried out and the calf muscles were split vertically. Clot was wiped out and a ragged piece of metal the size of a hazel nut was removed. It took little more swabbing to expose the posterior tibial artery, veins and nerve. There was incomplete division of the artery so retraction had not taken place and a ligature was tied round each end. The nerve had haemorrhage in the sheath and did not appear to be divided. I have no note regarding the veins. The wound was packed and dressings applied.

Next day, we had the long drive to Tobruk. The 62 nd General Hospital dealt with most of the desert casualties, but at the time of this visit little surgery was in progress.

On the return journey $I$ looked in at the 2 nd Indian C.C.S. and found no casualties had been evacuated since $I$ was there. The man in whose leg $I$ was interested was comfortable, the foot warm and toes mobile. Later I was to see the patient at the base with a healed wound, satisfactory circulation and probably no impairment of function or sensation dependent on the posterior tibial nerve.

\section{Diagnosis}

\section{Comment}

The appearance of a distended calf subsequent to trauma should be as well known as is the "flaying of the leg" seen too often after road accidents today. It seems likely that both will be remembered by anyone who has seen them. I have never taken nor seen a clinical photograph depicting the pathological shape arising from distension of the calf. This probably never occurs if there is a severe haemorrhage or if blood oozes our persistently. It follows when one or both wounds are partly or wholly obstructed. This occlusion may be due to a piece of clothing forced in or a foreign body but is more often man made by the insertion of a swab or length of bandage to stop external bleeding, which it does; blood then distends the calf and passes downwards to the ankle. Tension increases in the calf and the pathognomonic shape develops. If infection occurs, gas organisms in the calf muscle are likely to increase the size and tension of the calf and pain will become aggravated.

\section{Operation}

A distended calf is sufficient indication for operation at the first opportunity. It is appreciated that surgeons working in forward areas in wartime, and in undeveloped country at all times, have to use discrimination regarding what operations are urgent, which patients can travel shortly after operation, by air or road, and which patients, although requiring operation, can be transferred to a surgical centre without endangering life or limb. This great demand on the surgeon's discretion in wartime is necessary to prevent overloading of forward medical units. Perhaps his task has been made a trifle easier by the speed of modern warfare and the use of air travel for evacuation. In this case the point is that a sufferer from a posterior tibial artery lesion is not in immediate danger of losing his life from haemorrhage if he is not bleeding externally, but the chance of complications and of the loss of the limb increases hourly. Hence the operation is an urgent one. In order to see the exact condition of the vessel adequate exposure is necessary. This is best achieved by the muscle split operation through the centre of the calf and the incision can be prolonged downwards along the medial side towards the edge of the tendo Achillis. The exposure of the artery in front of the calf muscles through an incision along the posterior border of the tibia may have been an exercise enjoyed more by examiners than candidates in an operative surgery examination, but it has no place in 
the surgery of acute trauma.

The use of a tourniquet is open to criticism, as it may cause damage to the vessel which it constricts; this and the complete absence of passage of blood through all vessels in the limb even for a short time may be deleterious to the future vascularity of the distal part of the limb. Its advantages to the surgeon working in a forward area are:-

1. It may be a more useful assistant than a pair of untrained hands.

2. It provides a bloodless field, thereby saving a lot of time and enabling the surgeon to see the exact condition of artery, veins and nerve.

3. It makes it possible to see precisely if the surgical procedure, such as ligation, has been carried out successfully.

4. It is most helpful in the prevention of errors, such as injury to the nerve by instruments or ligation.

Under difficult conditions such as bad lighting the use of the tourniquet is essential for the success of the operation.

\section{Sequelae}

The following remarks refer to the cases in young men when there was a late operation or none; I have not seen an injury to the posterior tibial artery in a man or woman of middle age or after.

I have no information about the many limbs amputated in forward areas, for the exact indication for such an operation was rarely recorded in any detail and was usually quickly forgotten, nor of the leg shattered by multiple missiles; such conditions are not pertinent to this particular lesion.

Surgeons have seen more vascular injury in the popliteal space than in the calf, but a number of us do not consider the latter to be less common.

\section{Local complications}

If there is little or no infection a vascular injury may be a small hole, tear, a partial division with continuity of part of the vessel wall or a complete division, usually with retraction of the proximal end. A traumatic aneurysm may follow any of these and is least likely when there is a complete arterial division. During the formation of such,

1. the blood supply to the extremity of the limb may be insufficient owing to the main blood supply being cut off and to pressure by clot on other vessels so that a collateral circulation is not adequate; and

2. nature's effort to compensate for the loss of all or most of the main blood supply may be counteracted by thoughtless application and retention of dressings, such as gauze or bandage bound around the limb in a first aid (or later) effort to stop primary or recurrent haemorrhage.

These are the commoner causes of gangrene of the foot due to calf injury in a young man.

When there is infection especially with anaerobic organisms secondary haemorrhage is common and although control of the first occasion may be successful, amputation is seldom avoided. If gas forming organisms preponderate general treatment with local exposure of the wound area may counteract the symptoms and signs. Should response be good, haemorrhage does not seem frequent and limbs may be saved. Antibiotics were not then available.

I have no knowledge of the consequences, years later, of ligation of the posterior tibial artery following injury. It is easy to think that once collateral circulation has been 
formed, it will last for the span of the man's life; if this shows evidence of failure, it will be more difficult to fill a gap in this artery, later in life, than some months after the initial injury. Maybe the surgeons of today doing such effective vascular surgery will advocate that the saving of a limb, by a primary ligation, should be followed in due course by a vascular graft.

The object of reporting this experience more than twenty years after is to remind the surgeon dealing with acute trauma today of the importance of diagnosis as well as of the surgery of the calf and in doing so to invite comment on my actions.

\section{Gallantry in Borneo}

From the London Gazette 9th December, 1966 for services in Borneo Territories: M.B.E.

To be additional member of the Military Division of the most Excellent Order of the British Empire, Major Bruce Christopher MCDERMotT, R.A.M.

\section{Despatches}

Mentioned in Despatches, Lieutenant-Colonel Sidney Bruce TeLForD, M.B. R.A.M.C. Major David Cecil WeEKS, M.B., R.A.M.C.

\section{Appointment}

The Queen has approved the appointment and promotion of Brigadier $\mathbf{P}$. Wheatley, D.S.O, M.B., F.R.C.S, to be Director of Army Surgery and Consulting Surgeon to the Army, with the rank of Major-General, in May, 1967, in succession to Major-General R. A. Stephen.

Percival Ross Wheatley, born at Westbury, Wiltshire on 4th May, 1909, was educated at St, Dunstan's College, Catford, and London University (Guy's) where he qualified M.R.C.S.(Eng), L.R.C.P.(Lond) and graduated M.B., B.S. in 1935 . He became a Fellow of the Royal College of Surgeons in 1940.

Commissioned in the Royal Army Medical Corps in May 1939, he has served in the United Kingdom, Egypt, France, North Africa, Italy, Far East, Korea, Ghana and BAOR Senior appointments have been as Professor of Surgery at the Royal Army Medical College, and Consulting Surgeon, Far East and BAOR.

Awarded the D.S.O. in Sicily in 1943 . He is married with one child. 